\title{
Temperature dependence of the sorption isotherms of cement-based materials: Heat of sorption and Clausius-Clapeyron formula
}

\author{
Stéphane Poyet ${ }^{*}$, Sébastien Charles \\ CEA, DEN, DPC, SCCME, Laboratoire d'Étude du Comportement des Bétons et des Argiles, F-91191 Gif sur Yvette Cedex, France
}

\section{A R T I C L E I N F O}

Article history:

Received 12 September 2008

Accepted 17 July 2009

\section{Keywords:}

Waste management

Radioactive waste

Concrete

Durability

Temperature

Adsorption

\begin{abstract}
A B S T R A C T
In the field of radioactive waste management the concrete structures are expected to undergo significant heating due to the waste thermal power and significant drying (in the French design, the temperature is not expected to exceed $80{ }^{\circ} \mathrm{C}$ ). The durability assessment of such structures thus requires the knowledge of the evolution of the water vapour sorption properties versus temperature. The latter can be easily estimated using the Clausius-Clapeyron (CC) equation: the approach presented hereafter requires the knowledge of the isosteric heat of adsorption and one desorption isotherm (at ambient or any other temperature). Moreover, it is shown that using the CC equation and the desorption isotherms at two different temperatures, it is possible to estimate accurately the desorption isotherm at any other temperature.
\end{abstract}

(c) 2009 Elsevier Ltd. All rights reserved.

\section{Introduction}

The durability assessment of concrete structures over long term periods requires the accurate knowledge of their hydric properties, since the water content appears to have a great impact on most durability related properties (creep, shrinkage, transport...). The water retention of any material is usually characterized using a water vapour sorption isotherm. The latter represent the amount of evaporable (free) water retained at equilibrium with an external environment as a function of its relative humidity $(\mathrm{RH})$ for a given constant temperature (isothermal conditions). In the case of cementitious materials, a lot of work has been done since the pioneering studies of Powers and Brownyard [1] and many materials have been characterized, from hardened $\mathrm{C}_{3} \mathrm{~S}$ pastes to modern concretes (high-performance or selflevelling concretes...). The great majority of these results were acquired at ambient temperature (that is to say at about $20^{\circ} \mathrm{C}$ ).

Nevertheless in the framework of radioactive waste management, the concrete structures for interim storage are expected to undergo significant heating due to the waste thermal power. In the French design of subsurface structures, the cooling should be achieved using natural convection with air taken from the outside. The concrete temperature is expected to reach up to $80^{\circ} \mathrm{C}$ in nominal conditions (without exceeding it) and the concrete structure is expected to undergo severe drying (due to the temperature increase of the ambient air) [2,3]. The durability assessment of these structures over 300 years thus requires the accurate knowledge of the sorption properties of concretes at such unusual

\footnotetext{
* Corresponding author.

E-mail address: stephane.poyet@cea.fr (S. Poyet).
}

temperature levels with particular interest in the first desorption (corresponding to the drying process).

Very few articles were published regarding the effect of temperature on water sorption isotherms of cementitious materials with special interest in the first desorption. In a recent study [4] the first desorption of a high-performance concrete (cured at $20^{\circ} \mathrm{C}$, the concrete composition is given in Table 1 of Appendix A) was characterized at $30^{\circ} \mathrm{C}$ and $80^{\circ} \mathrm{C}$. The results are depicted in Fig. 1; the GAB model [5] was used to fit the results as a guide for the eyes. The GAB model is an evolution of the well-known BET model introducing a third parameter $k$ which extends its domain of validity almost over the whole $\mathrm{RH}$ range. More information about the fitting can be found in [4], the GAB model is described in detail in [5-7]. The equation of the GAB model is:

$w=\frac{C k w_{\mathrm{m}} h}{(1-k h)[1+(C-1) k h]}$

where $w$ is the water content (by mass, it is equal to the ratio of the mass of water and the mass of dry solid), $h$ is the relative humidity and $C, k$ and $w_{\mathrm{m}}$ are three positive parameters. The values of the three parameters of the GAB model are reported in Table 2 of Appendix A.

One can see the important effect of temperature on the experimental curve: at $30^{\circ} \mathrm{C}$ the isotherm is almost a straight line whereas at $80{ }^{\circ} \mathrm{C}$ the shape is greatly modified (non linearity). This leads to the significant decrease of the amount of adsorbed water for a given relative humidity $(R H)$ at higher temperatures. This effect is not the same over the whole $R H$ range: for instance at saturation $(R H=100 \%)$ the reduction is about $0.9 \%$ (absolute value), whereas it is about $2.5 \%$ at $R H=80 \%$ [4]. 


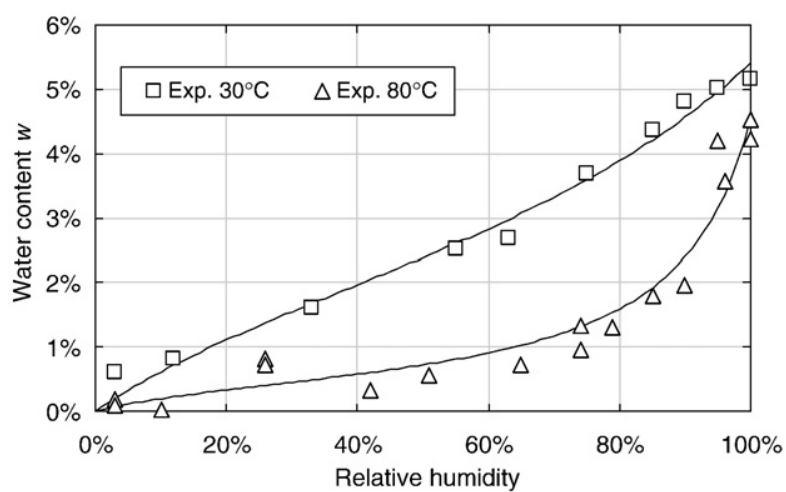

Fig. 1. Experimental characterization of the first desorption isotherms at 30 and $80{ }^{\circ} \mathrm{C}$ of a high performance concrete cured at $20{ }^{\circ} \mathrm{C}$ [4]. The two solid lines represent the fitting of the results using the GAB model.

The same conclusions can be drawn on the basis of the results obtained by Hundt and Kantelberg [8] and more recently by Ishida et al. [9]. In addition, Hundt and Kantelberg have characterized the first desorption isotherm of different cementitious materials (from cement paste to concrete) for four temperatures $\left(20^{\circ} \mathrm{C}, 45^{\circ} \mathrm{C}, 57.5^{\circ} \mathrm{C}\right.$ and $70^{\circ} \mathrm{C}$ ): They have shown that the impact of temperature was also significant even at $45^{\circ} \mathrm{C}$ (see the results in Fig. 2). The origin of this phenomenon was discussed in a previous article [4]. It is believed by the author that it is neither due to the microstructure modification induced by temperature nor the water properties evolution. As a matter of fact, adsorption is known to be an exothermic process $[10,11]$; according to the principle of Le Chatelier and the law of Van't Hoff [12] which state that an exothermic process is hindered when temperature is increased (and reciprocally it is enhanced when temperature is decreased) a temperature increase promotes desorption. This leads to a decrease of the number of adsorbed molecules and then a fall in the water content [4].

From those results, it can be concluded that the impact of temperature on the first desorption of cementitious materials is very important. As a consequence, it appears compulsory to account for this phenomenon in the durability assessment of concrete structures subjected to temperatures higher than the ambient, and the evolution of the first desorption isotherm versus temperature must be known. Experimental characterization of this evolution would be problematic due to the time needed to reach equilibrium and the number of experiments needed to cover the whole temperature range. It appears clearly that a method for accurate prediction of the isotherm evolution versus temperature would be a great help.

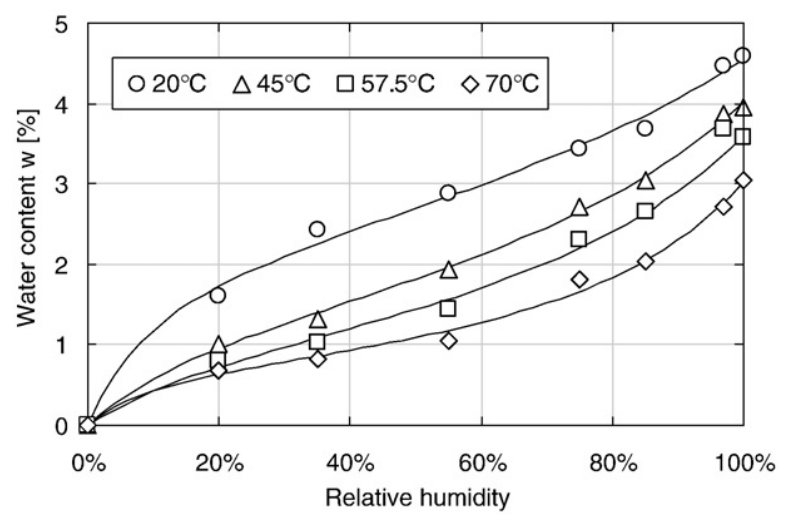

Fig. 2. First desorption isotherm of a concrete (labelled 'beton 5') for four temperatures, after Hundt and Kantelberg [8]. The solid lines stand for the fitting of the experimental results using the GAB model.
Such a method is presented in this article. It is assumed that the isotherm evolution is only due to the "thermal desorption": that is to say the shift of equilibrium (adsorbed water-vapour) induced by the temperature increase. The potential microstructure changes are not considered. The method is based on the Clausius-Clapeyron (CC) formula which describes the heat involved in the sorption process. This method allows, on the basis of the results obtained at only two temperatures, an accurate and reliable estimation of the isotherm for any other temperature. It is based on the description of the evolution of the sorption heat as a function of the amount of water adsorbed. As illustration and validation, this method is applied to the high performance concrete [4] and then to the concrete characterized by Hundt and Kantelberg [8].

\section{Theoretical considerations}

\subsection{Equation of Clausius-Clapeyron}

The Clausius-Clapeyron (CC) equation can be used to describe the heat involved in the sorption process [10]:

$Q_{\mathrm{st}}(w)=-R\left[\frac{\partial \ln (p)}{\partial\left({ }^{1} / T\right)}\right]_{w}$

where $p$ and $T$ are the pressure of the adsorbate (water vapour in our case) at equilibrium (in $\mathrm{Pa}$ ) and the absolute temperature (in $\mathrm{K}$ ); $R$ is the ideal gas constant $(R=8.314 \mathrm{~J} / \mathrm{mol} / \mathrm{K})$ and $Q_{\mathrm{st}}$ stands for the amount of energy involved in the sorption process; it is known as the isosteric heat of sorption (it is also known as the enthalpy of sorption in $\mathrm{J} / \mathrm{mol}$ ). Note that in Eq. (2). the subscript $w$ indicates that the derivation operation must be carried out for a constant amount adsorbed $w$ (in isosteric conditions).

The demonstration of this equation can be found for instance in [13-16]. It is based on two approximations: the adsorbate is considered as an ideal gas and the volume of the adsorbed phase is neglected in comparison to the gas bulk phase. These two assumptions are reasonable at atmospheric pressure (that is always the case for water vapour adsorption in cementitious materials) yet they are known to induce deviation from reality for high pressures (up to several atmospheres) [17].

\subsection{Isosteric heat of sorption}

Integrating Eq. (2) between the two equilibrium states $\left(T_{1}, p_{\mathrm{v} 1}\right)$ and $\left(T_{2}, p_{\mathrm{v} 2}\right)$ for any arbitrary constant water content $w$ leads to Eq. (3):

$Q_{\mathrm{st}}(w)=R \ln \left[\frac{p_{\mathrm{v} 1}(w)}{p_{\mathrm{v} 2}(w)}\right]\left(\frac{T_{1} T_{2}}{T_{1}-T_{2}}\right)$

where the two absolute temperatures $T_{1}$ and $T_{2}$ are different and $p_{\mathrm{v} 1}$ and $p_{\mathrm{v} 2}$ are the vapour pressures at equilibrium with the (constant) water content $w$. This Eq. (3) can be used to estimate the heat of sorption of the high performance concrete which has been characterized at $30^{\circ} \mathrm{C}$ and $80^{\circ} \mathrm{C}$ in [4] (Fig. 1). Obviously, the number of experimental temperatures (only two) is too low to give an accurate evolution of the isosteric heat of sorption; the goal of this application is to serve as an illustration of the use of the CC equation. It is also expected to yield valuable information about water vapour adsorption in cementitious materials.

Due to the lack of experimental data the calculation of the isosteric heat of sorption was carried out using the fitted GAB functions. The vapour pressure at equilibrium with the arbitrary water content $w$ at the temperature $T_{i}$ was calculated using the GAB reciprocal relation:

$p_{\mathrm{vi}}(w)=\frac{p_{\mathrm{vs}}\left(T_{i}\right)}{2 k_{i}\left(1-C_{i}\right)}\left[\alpha_{i}-\sqrt{\alpha_{i}^{2}-4\left(1-C_{i}\right)}\right]$ 
where $p_{\mathrm{vs}}\left(T_{i}\right)$ is the saturation vapour pressure for the temperature $T_{i}$ and $\alpha_{i}$ is equal to:

$\alpha_{i}=2+\left[\frac{w_{\mathrm{m} i}}{w}-1\right] C_{i}$

where $C_{i}, k_{i}$ and $w_{\mathrm{m} i}$ are the three parameters of the GAB model for the fitting of the experimental results obtained at the temperature $T_{i}$ (see Table 2). Taking arbitrary values for $w$ allows calculating the vapour pressures at equilibrium for the two temperatures $30{ }^{\circ} \mathrm{C}$ and $80^{\circ} \mathrm{C}$ and then the corresponding isosteric heat of sorption $Q_{s t}(w)$. In practise a total number of 32 different water content values were used, ranging from $0 \%$ to $4.60 \%$ (the maximal value obtained experimentally at $80^{\circ} \mathrm{C}$ ).

The variation of the pressure at equilibrium with the constant amount of adsorbed water $w$ as a function of the inverse of the temperature applied is plotted in Fig. 3. Each line stands for a different constant water content $w$. The low water contents are located at the bottom of the graph (low vapour pressure) whereas the high water contents are located in the upper part of the graph (high vapour pressure). This chart is a graphical illustration of the CC equation, since according to Eq. (2) the slope of each line is equal to $-Q_{\mathrm{st}}(w) / R$.

The evolution of the isosteric heat of sorption versus the water content (as obtained from the slopes of lines in Fig. 3 ) is plotted in Fig. 4 (the values obtained are reported in Table 4). One can note that for low water contents, the isosteric heat first increases and reaches a maximal value ( $Q_{\mathrm{st}} \approx 68 \mathrm{~kJ} / \mathrm{mol}$ ) for $w \approx 0.5 \%$. It then decreases slowly and tends towards $43 \mathrm{~kJ} / \mathrm{mol}$ for high water contents. The high values observed for low water contents are representative of strong bonding between the adsorbed water molecules and the cementitious substrate. The isosteric heat decrease according to the increase of water content can be related to the decrease of the influence of the substrate with the increase of the distance between the adsorbed water molecules and the substrate. The value reached at high water contents $(\sim 43 \mathrm{~kJ} / \mathrm{mol})$ is representative of the average water condensation enthalpy between 30 and $80{ }^{\circ} \mathrm{C}$ [18]: it can be considered that there is no more influence of the substrate, water molecules are bound the ones to the others.

\section{Prediction of the effect of temperature}

\subsection{Presentation of the methodology and main results}

We have just seen that the $\mathrm{CC}$ formula can be used on the basis of sorption isotherms at different temperatures to calculate the isosteric heat of sorption. Nevertheless, knowing the evolution of the isosteric heat of sorption, it can also be used to estimate the impact of

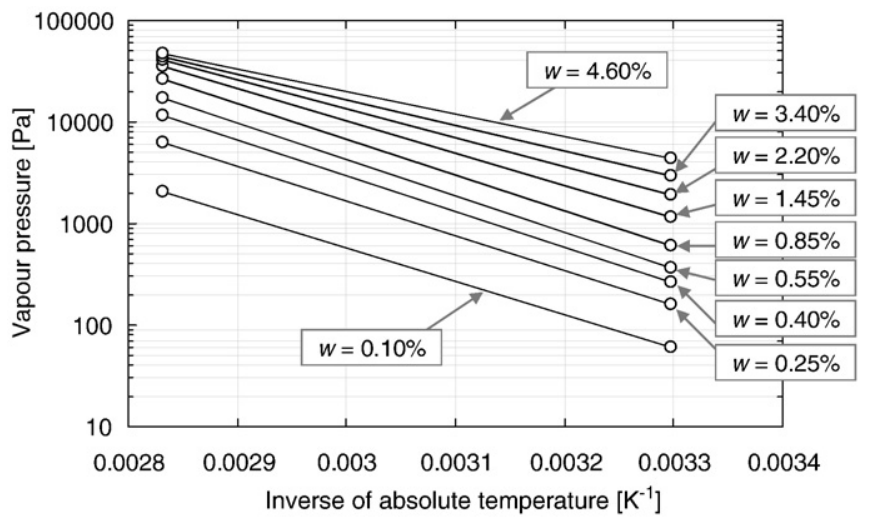

Fig. 3. Isosteric chart (isosteres of desorption) of the experimental results for the high performance concrete tested in [4]: application of Eq. (3) between $30{ }^{\circ} \mathrm{C}$ and $80{ }^{\circ} \mathrm{C}$. Each line corresponds to a different (constant) water amount w.

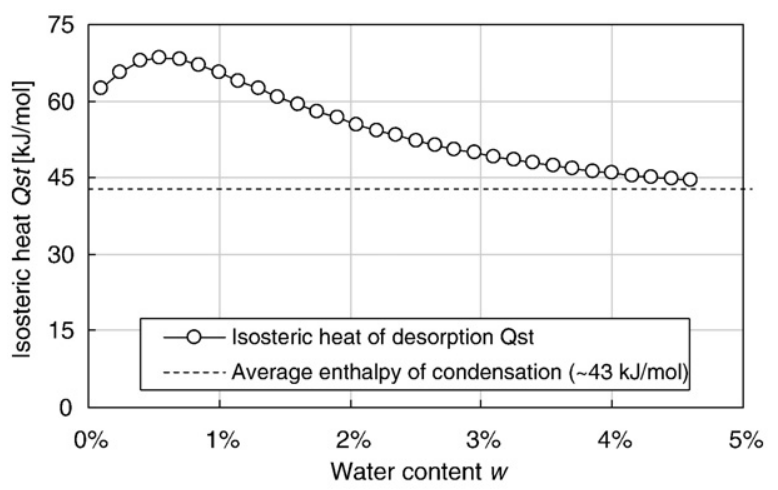

Fig. 4. Isosteric heat of sorption $Q_{s t}$ as a function of the water content $w$ for the high performance concrete tested in [4].

temperature and yield a prediction of the evolution of sorption isotherms for different temperatures. Integrating Eq. (2) between the two states $\left(T_{1}, p_{\mathrm{v} 1}\right)$ and $\left(T_{2}, p_{\mathrm{v} 2}\right)$ at equilibrium with the constant water content $w$ leads to:

$R H\left(T_{1}, w\right)=R H\left(T_{2}, w\right) \frac{p_{\mathrm{vs}}\left(T_{2}\right)}{p_{\mathrm{vs}}\left(T_{1}\right)} \exp \left[\frac{Q_{\mathrm{st}}(w)}{R}\left(\frac{T_{1}-T_{2}}{T_{1} T_{2}}\right)\right]$

where $R H\left(T_{i}, w\right)$ is the relative humidity at equilibrium with the adsorbed water content $w$ at the temperature $T_{i}$ (with $i=\{1 ; 2\}$ ). In Eq. (6), the sorption isotherm is assumed to be known at the temperature $T_{2}$ (the relation between the water content $w$ and the relative humidity $R H$ is known) in order to compute its evolution at the temperature $T_{1}$.

Eq. (6) was applied to the high performance concrete described earlier [4] on the basis of the results obtained at $30^{\circ} \mathrm{C}$ and $80^{\circ} \mathrm{C}$, the desorption isotherms were then computed for temperatures ranging from $5{ }^{\circ} \mathrm{C}$ to $105^{\circ} \mathrm{C}$. An arbitrary constant water content $w$ was chosen and $R H\left(T_{1}, w\right)$, the relative humidity at equilibrium at the temperature $T_{1}$ $\left(80^{\circ} \mathrm{C}\right)$ with the water content $w$, was computed using Eq. (6). The relative humidity at equilibrium at the temperature $T_{2}\left(30^{\circ} \mathrm{C}\right)$ was estimated using the GAB inverse function defined in Eqs. (4)-(5). The isosteric heat of sorption determined above (depicted in Fig. 4) was used and the reference curve was the one obtained at $30^{\circ} \mathrm{C}$. It was also verified that the same results were obtained using the $80^{\circ} \mathrm{C}$ results as a reference.

The resulting predicted desorption isotherms for different temperatures are presented in Fig. 5. The two solid lines stand for the experimental results at $30^{\circ} \mathrm{C}$ and $80^{\circ} \mathrm{C}$ fitted using the GAB model and used for the calculation of the isosteric heat of sorption. The other curves (with open symbols) stand for the prediction for temperatures ranging from $5{ }^{\circ} \mathrm{C}$ up to $105{ }^{\circ} \mathrm{C}$. One can note the spectacular impact of

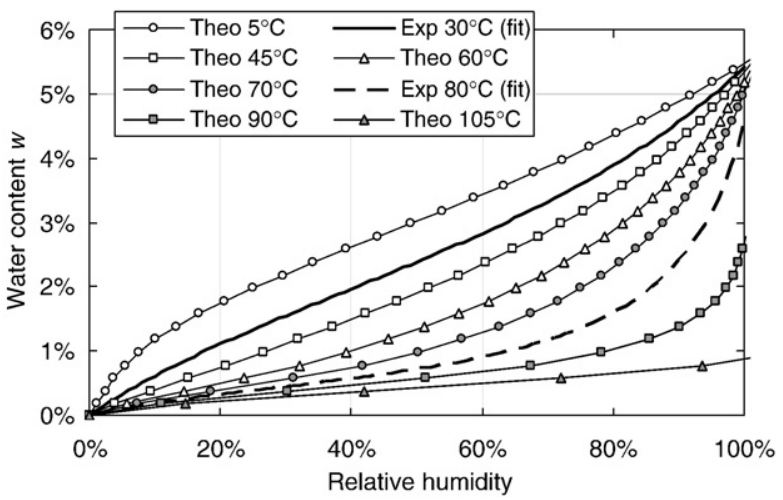

Fig. 5. Prediction of the impact of temperature (from $5{ }^{\circ} \mathrm{C}$ up to $105^{\circ} \mathrm{C}$ ) on the first desorption isotherms for the concrete described in [4] (solid lines stand for the experimental results obtained at $30^{\circ} \mathrm{C}$ and $80^{\circ} \mathrm{C}$ fitted using the $\mathrm{GAB}$ model and dotted lines stand for the predictions for temperatures ranging from $5{ }^{\circ} \mathrm{C}$ to $105{ }^{\circ} \mathrm{C}$ ). 
temperature on the (estimated) first desorption isotherm of the studied high-performance concrete.

The general shape of the isotherm can be greatly modified according to the considered temperature: thanks to the measurements it was found to be almost a straight line at $30^{\circ} \mathrm{C}$ and a non linear curve with an upward deviation at $80^{\circ} \mathrm{C}$, whereas the CC equation yields an almost type I isotherm at $105^{\circ} \mathrm{C}$ (representative of monomolecular adsorption without capillary condensation).

Another expected consequence of the temperature variation is the evolution of the adsorbed water amount: the lower the temperature, the higher the amount of adsorbed water. This phenomenon is expected to be observed at any temperature over the whole $\mathrm{RH}$ range and even at saturation (i.e. for $R H=100 \%$ ). This can also be witnessed on the results of Hundt and Kantelberg [8].

Another important point concerning the impact of temperature is the absence of temperature threshold: any temperature modification is expected to induce the modifications presented above on the desorption curve. For instance, the desorption isotherm at $20^{\circ} \mathrm{C}$ is expected to be different from the one measured at $30^{\circ} \mathrm{C}$ in spite of the low difference of temperature. Moreover, it appears that the evolution of the desorption isotherm between $5{ }^{\circ} \mathrm{C}$ and $30^{\circ} \mathrm{C}$ (which are assumed to be representative of the ambient temperature variation for an average concrete structure in France) cannot be considered negligible: for instance, at $R H=40 \%$ the water content is expected to fall from $2.6 \%$ at $5{ }^{\circ} \mathrm{C}$ down to $2.0 \%$ at $30{ }^{\circ} \mathrm{C}$.

All the conclusions above are drawn on the basis of the application of the CC formula using the first desorption isotherm of a highperformance concrete obtained experimentally at $30{ }^{\circ} \mathrm{C}$ and $80{ }^{\circ} \mathrm{C}$. The confidence in these conclusions relies on the following validation.

\subsection{Validation of the methodology}

The methodology introduced in the previous paragraph was applied to some of the results of Hundt and Kantelberg [8] in order to estimate the ability of the $\mathrm{CC}$ equation to predict the evolution of the desorption curves as a function of temperature. The results presented in Fig. 2 were used (labelled 'beton 5' in Ref. [8]). In this part, the isosteric heat of sorption was calculated using the results obtained at only two temperatures and the desorption isotherm was computed using Eq. (6). for the two other temperatures and then compared to the experimental results.

First, the isosteric heat of sorption was estimated (the values obtained are reported in Table 5) using the experimental results obtained at $20^{\circ} \mathrm{C}$ and $70{ }^{\circ} \mathrm{C}$ (see Fig. 7) and the theoretical desorption isotherm at $45^{\circ} \mathrm{C}$ and $57.5^{\circ} \mathrm{C}$ was then computed. The experimental curve at $20^{\circ} \mathrm{C}$ was used as a reference for the calculation, it was verified that the same results were obtained using the experimental isotherm at $70{ }^{\circ} \mathrm{C}$ as reference. Fig. 6 presents the comparison

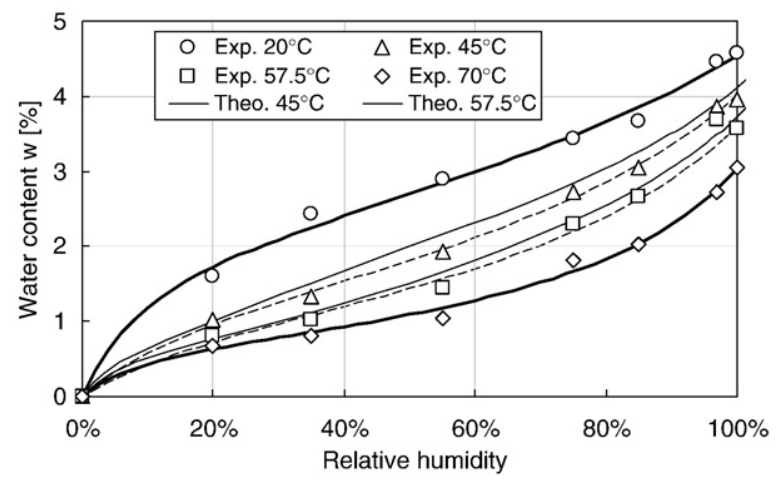

Fig. 6. Comparison between the desorption isotherms measured and predicted at $45{ }^{\circ} \mathrm{C}$ and $57.5^{\circ} \mathrm{C}$ on the basis of the measured results at $20^{\circ} \mathrm{C}$ and $70{ }^{\circ} \mathrm{C}$ only (from Hundt and Kantelberg [8]). The two dotted lines stand for the GAB fitting of the experimental results at $45{ }^{\circ} \mathrm{C}$ and $57.5{ }^{\circ} \mathrm{C}$

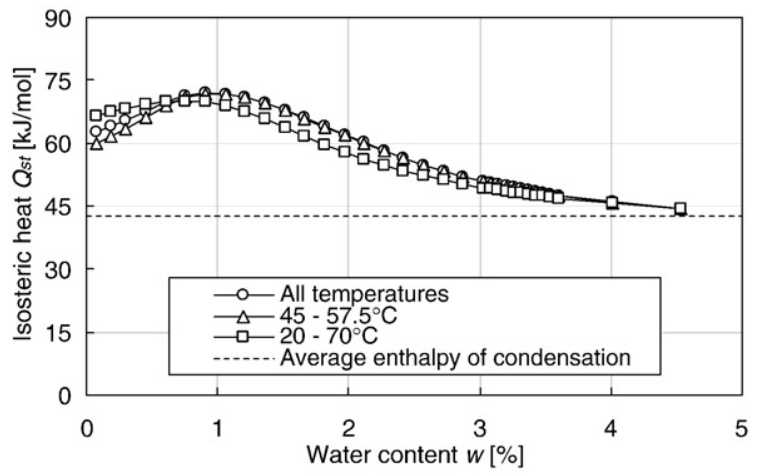

Fig. 7. Evolution of the isosteric heat of sorption $Q_{s t}$ for 'beton 5 ' on the basis of the results obtained by Hundt and Kantelberg [8].

between the predicted isotherm at $45{ }^{\circ} \mathrm{C}$ and $57.5{ }^{\circ} \mathrm{C}$ and the experimental results obtained by Hundt and Kantelberg [8]. One can see the good correspondence between the measurements and the theoretical curves predicted using CC.

Nevertheless, the estimation of the isotherms was done on the basis of the results for the two extreme temperature values for which the measured difference is maximal. One can thus expect this calculation to give the best results. Another set of predictions was then carried out: the isosteric heat of sorption was determined (the values obtained are reported in Table 5) on the basis of the results obtained at $45^{\circ} \mathrm{C}$ and $57.5^{\circ} \mathrm{C}$ ( see Fig. 7) and the desorption isotherms at $20^{\circ} \mathrm{C}$ and $70^{\circ} \mathrm{C}$ was then estimated using CC. The results are presented in Fig. 8. Once more the correspondence between the measured and the predicted results is good.

In both cases, the prediction of the isotherm yield good results: the shape of the curves is clearly reproduced and the difference between the measured and the predicted water contents remains limited. The latter was characterized using the following function:

$E(T, R H)=\frac{\left|w_{\text {theo }}(T, R H)-w_{\text {exp }}(T, R H)\right|}{w_{\text {exp }}(T, R H)}$

where $E$ is the relative difference between measurements and prediction and $w_{\text {theo }}$ and $w_{\exp }$ are the water content calculated using CC and obtained experimentally respectively. Fig. 9 presents the evolution of the relative difference $E$ between the measured water contents and the ones predicted using CC. One can note that in most cases the relative difference remains very limited (its values range from $1 \%$ up to $8 \%$, with a mean value which is less than $5 \%$ ) except for $R H=35 \%$ and $R H=55 \%$ for which the relative difference reaches

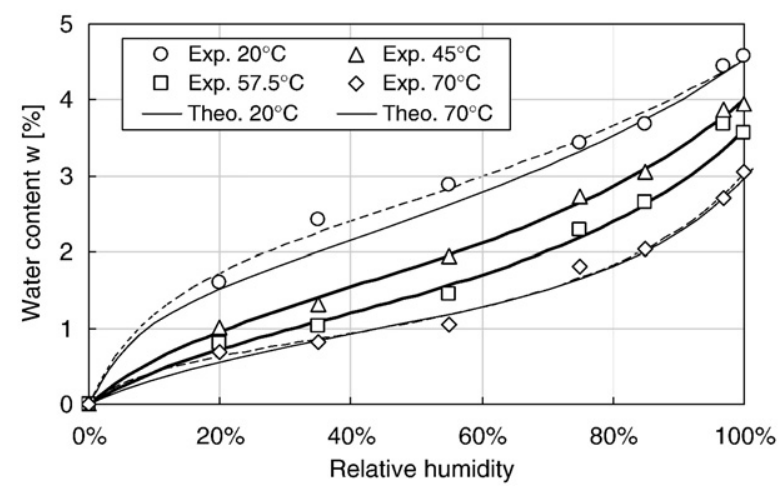

Fig. 8. Comparison between the desorption isotherms measured and predicted at $20{ }^{\circ} \mathrm{C}$ and $70{ }^{\circ} \mathrm{C}$ on the basis of the results measured at $45^{\circ} \mathrm{C}$ and $57.5^{\circ} \mathrm{C}$ only, (from Hundt and Kantelberg [8]). The two dotted lines stand for the GAB fitting of the experimental results at $20^{\circ} \mathrm{C}$ and $70{ }^{\circ} \mathrm{C}$. 


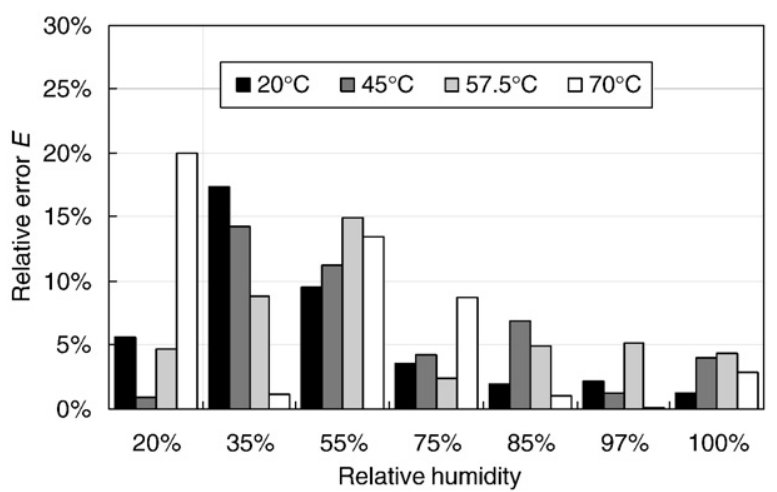

Fig. 9. Evolution of the relative difference between the estimated and measured adsorbed water amounts for different $R H$ in the case of beton 5 [8].

values ranging from $10 \%$ to $20 \%$. This is mainly due to the scattering observed in the fitting of the experimental results using the GAB model for these two RHs (Fig. 2).

\section{Discussion}

\subsection{Heat of sorption of cementitious materials}

Fig. 5 shows the important impact of temperature on the first desorption isotherm. The only parameter controlling this evolution versus temperature is the isosteric heat of sorption $Q_{s t}$ (see Eq. (2)).

There are very few results in the scientific literature about the heat of sorption for cementitious materials. According to the authors' knowledge, Powers and Brownyard [1] were the first to characterize the heat of sorption of cementitious materials. They used the so-called heat-of-solution method and two different cement pastes ( $W /$ $C=0.50$ ). The experiment consisted in the dissolution of dry pastes followed by the dissolution of similar samples containing adsorbed water. The comparison of the heat involved in the two processes allowed them to estimate the differential heat of adsorption $Q_{a}[\mathrm{cal} / \mathrm{g}$ ] and to propose the following function:

$Q_{\mathrm{a}}=\frac{858}{\left(1.31+\frac{w}{w_{\mathrm{m}}}\right)^{2}}$

where $w_{\mathrm{m}}$ is the monolayer capacity of the studied cement pastes: the ratio $\left(w / w_{\mathrm{m}}\right)$ represents the number of adsorbed layers. According to the Hess's law $[1,12,19]$, the isosteric heat $Q_{\mathrm{st}}[\mathrm{kJ} / \mathrm{mol}]$ can thus be estimated by adding the latent heat of condensation $L=42.7 \mathrm{~kJ} / \mathrm{mol}$ :

$Q_{\mathrm{st}}=\left(L+Q_{\mathrm{a}}\right)=42.7+\frac{64.6}{\left(1.31+\frac{w}{w_{\mathrm{m}}}\right)^{2}}$

Fig. 10 presents the evolution of the heat of sorption (differential and isosteric) according to the law proposed by Powers and Brownyard [1]. The heat of sorption is a decreasing function of the water content: the more the water content, the lower the heat of sorption. The maximal value of the isosteric heat is about $80 \mathrm{~kJ} / \mathrm{mol}$. According to Eq. (9), the value decreases with the increase of the water content and the curve tends towards the latent heat of condensation $(42.7 \mathrm{~kJ} / \mathrm{mol})$ for high water contents.

Results of the same kind have been obtained using three hardened cement pastes (two were steam-cured at $97{ }^{\circ} \mathrm{C}$ and the last one was cured at room temperature) with various $\mathrm{W} / \mathrm{C}$ ratios by Radjy et al. [20] and Sellevold and Bjøntegaard [21]. The experiments were carried out using the so-called Thermo Piestic Analyser system (TPA system) and the sorption isotherms were characterized for temperatures ranging from $0{ }^{\circ} \mathrm{C}$ to $80^{\circ} \mathrm{C}$. The isosteric heat of sorption was

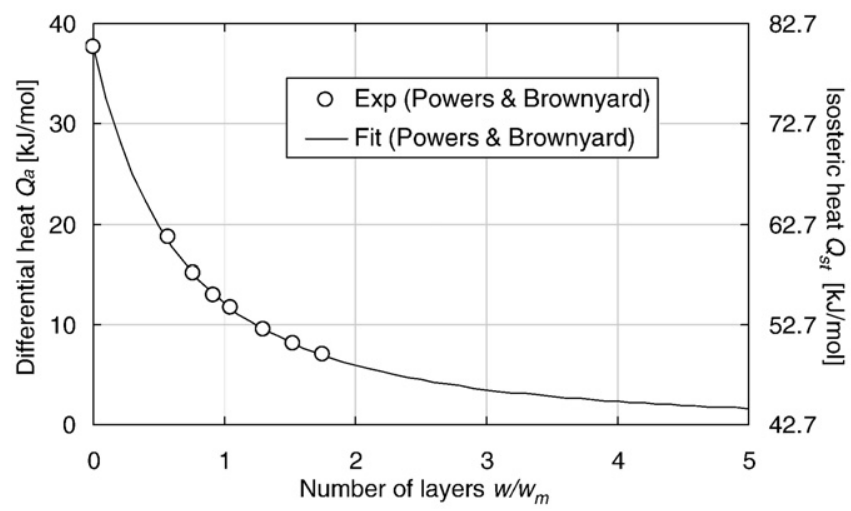

Fig. 10. Evolution of the differential $\left(Q_{\mathrm{a}}\right)$ and isosteric $\left(Q_{\mathrm{st}}\right)$ heats of sorption as functions of the water content $w$ (according to Powers and Brownyard [1]).

then estimated on the basis of the results acquired for all the materials tested. Similar evolution as the one depicted on Fig. 10 was obtained: the maximal value reached is about $80 \mathrm{~kJ} / \mathrm{mol}$ for the three cement pastes, the isosteric heat decreases when the water content increases and it tends towards $42.7 \mathrm{~kJ} / \mathrm{mol}$ for high water contents.

Nielsen and Kronholm [19] studied the $R H$ at equilibrium above a mortar $(W / C=0.2)$ for temperatures ranging from $20^{\circ} \mathrm{C}$ to $35^{\circ} \mathrm{C}$. They derived the differential sorption enthalpy using the CC equation. Their results show a good correspondence with the empirical formula proposed by Powers and Brownyard [1] (see Eq. (8)) for two experiments (among three): the same order of magnitude was found and the same decrease with the increase of $R H$ was observed. Nonetheless, their results do not cover the whole $R H$ range (typically from $50 \%$ to $95 \%$ ) and one experiment deviated from the proposed formula (the values obtained are twice as much as the empirical equation).

Fig. 11 depicts the comparison between the isosteric heats of sorption as obtained in this study, and after Hundt and Kantelberg (beton 5) [8] and Powers and Brownyard [1]. The three curves show a similar pattern yet the two curves obtained using the results from Poyet [4] and Hundt and Kantelberg [8] slightly differ from the curve proposed by Powers and Brownyard [1]. The isosteric heat of sorption first increases with the water content until a maximum is reached, it then decreases and tends towards the heat of condensation $L=42.7 \mathrm{~kJ} / \mathrm{mol}$. Note that the slope of both increasing and decreasing phases is different for the two concretes. Also note that the two maximal values reached are different ( 68 and $72 \mathrm{~kJ} / \mathrm{mol}$ for Poyet and Hundt and Kantelberg respectively). This comparison tends to indicate that the evolution of the isosteric heat of sorption depends on the considered cementitious material.

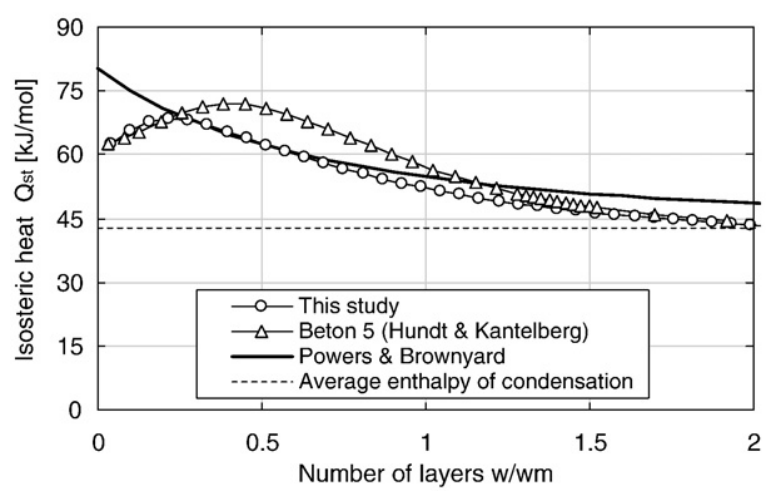

Fig. 11. Comparison between the isosteric heats of sorption obtained in this study, derived from the results of Hundt and Kantelberg [8] and proposed by Powers and Brownyard [1]. 
In the scientific literature the decrease of the isosteric heat of sorption with the increase of the water content and an asymptotic value about $45 \mathrm{~kJ} / \mathrm{mol}$ is generally observed for many different materials: food or aromatic leaves [22-30], soils and minerals [31-36] or engineered materials [37-43]. A monotonic decrease is generally reported. The latter is generally explained by the reduction of the influence of the hydrophilic surface (attractive forces) induced by the increase of the numbers of adsorbed layers [44]. The asymptotic value of $45 \mathrm{~kJ} / \mathrm{mol}$ is representative of water-to-water bonding (liquid state).

Yet an increase for low water contents was observed for porous carbons [40-43] and carbohydrate polymers [37]. In the case of porous carbons the low initial isosteric heat of sorption (between 15 and $20 \mathrm{~kJ} / \mathrm{mol}$ ) is explained by a very small number of hydrophilic sites. The increase is attributed to the creation of water clusters (H-bonding between water molecules). In the case of carbohydrate polymers [37] the initial heat of sorption was found to be higher than $45 \mathrm{~kJ} / \mathrm{mol}$ (about $60 \mathrm{~kJ} / \mathrm{mol}$ ), the increase (up to $70-80 \mathrm{~kJ} / \mathrm{mol}$ ) was associated to the polymer matrix swelling which would activate new adsorption sites. Similar increase for low water contents were observed with carrot [45] and bentonite [46] but no clear explanation was given.

In the case of montmorillonite, Zhang and Low [47] studied the evolution of the heat of immersion in relation to the initial water content. They showed that the heat of immersion did not decrease continuously: the latter passed by a minimum and then a maximum to eventually tend towards zero. They thus showed that energy was consumed in order to expand the montmorillonite layers. In our case, it is difficult to draw any conclusion. One has to keep in mind that the increase of the isosteric heat of sorption was found on the basis of smoothed experimental results. Moreover the small number of results for low water contents is expected to induce uncertainties in estimating the isosteric heat of sorption. The maximum observed in the evolution of the isosteric heat of desorption might just be an artefact of the estimation process as well as representative of a real phenomenon. It then appears that more studies on cementitious materials are needed, with a special interest in low water contents.

\subsection{About the prediction of the effect of temperature}

It was shown above that the CC equation is a powerful tool for the prediction of the impact of temperature on the first desorption isotherm. Only one parameter is needed (the isosteric heat of sorption $Q_{s t}$ ) to describe the evolution of desorption isotherms versus temperature: knowing the desorption curve at one temperature and using CC, one can accurately predict the curves for any other temperature (see an example on Fig. 5 and see Figs. 6 and 8 for the validation).

The main issue of this method is that the isosteric heat of sorption $Q_{\text {st }}$ must be known. It was shown above that the latter can be identified using two different isotherms (at two different temperatures). Of course the reliability of the method (and then of the results obtained) depends on the quality of the input data (experimental results).

Nonetheless, obtaining the sorption isotherm at different temperatures is a long and difficult task which may be hard to accomplish. The main question is thus: can the isotherms at different temperatures of a concrete be estimated using the isosteric heat of sorption obtained on another concrete? Or using a generic evolution such the one proposed by Powers and Brownyard [1]? These questions are interesting given that the three evolutions drawn on Fig. 11 show a similar pattern.

To answer this question the desorption isotherm of beton 5 [8] at $45^{\circ} \mathrm{C}, 57.5{ }^{\circ} \mathrm{C}$ and $70{ }^{\circ} \mathrm{C}$ was estimated using CC. The reference curve was the one obtained at $20^{\circ} \mathrm{C}$. Three different isosteric heats of sorption were used for the computations: the one obtained in this study, the one proposed by Powers and Brownyard [1] and the proper one derived from the results obtained at the four temperatures. Fig. 12 presents the comparison between the three isosteric heats of sorption

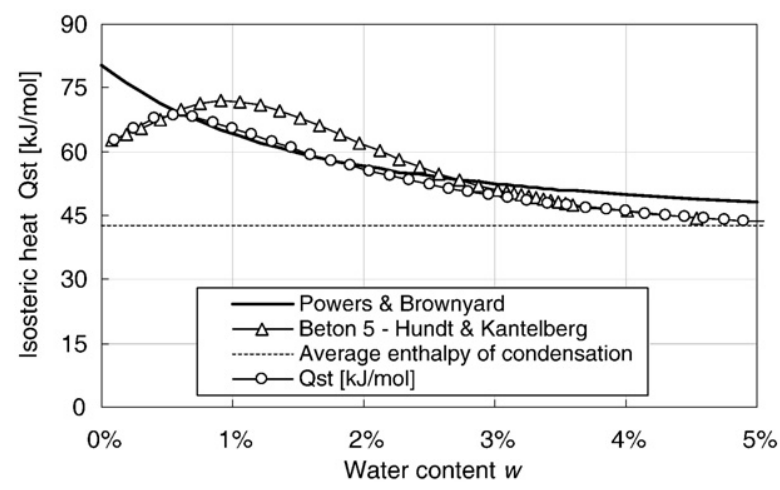

Fig. 12. Evolution of the isosteric heats of sorption $Q_{s t}$ used for the estimation of the desorption isotherm evolution versus temperature for beton 5 [8].

versus the water content $w$ of beton 5 . One can note that beyond $w \approx 1 \%$ the three curves are very similar.

Fig. 13 presents the isotherm at $70{ }^{\circ} \mathrm{C}$ predicted using the three isosteric heats of sorption depicted on Fig. 12. One can see that the curve (dotted line) estimated using the data derived from the experimental points for the four temperatures fit very well the experimental results as demonstrated earlier. The two other curves (obtained using the isosteric heats of sorption proposed by Powers and Brownyard and estimated in this study) do not fit as well. In each case, the experimental pattern is clearly not reproduced (for instance using Powers and Brownyard heat of sorption, the knee and the upward deviation are not reproduced). Moreover, it can be seen that the water contents predicted using the heats of sorption from Powers and Brownyard and this study greatly differ from the values obtained experimentally. The difference was characterized using the relative error $E$ defined in Eq. (7); the results are presented in Fig. 14. One can see that the relative error obtained using unrelated isosteric heats can be very large (up to 75\%) whereas the use of proper data leads to an error included in the range $0 \%-12 \%$. Note that the relative error presented in Fig. 14 is different from the one from Fig. 9. This is due to the fact that the isosteric heat used in Fig. 14 was identified using the data of the four temperatures $(20,45,57.5$ and $70{ }^{\circ} \mathrm{C}$ ) whereas only two temperatures were used in Fig. $9\left(20\right.$ and $70{ }^{\circ} \mathrm{C}$ and 45 and $57.5^{\circ} \mathrm{C}$ ).

It can be concluded from these results that the prediction of desorption isotherm evolution with temperature is strongly sensitive to the isosteric heat of sorption. A reliable prediction thus requires an accurate description of the isosteric heat of sorption for the cementitious material in question. Generic equations such as the one proposed by Powers and Brownyard [1] or the two other evolutions derived in this study (from Poyet [4] and Hundt and

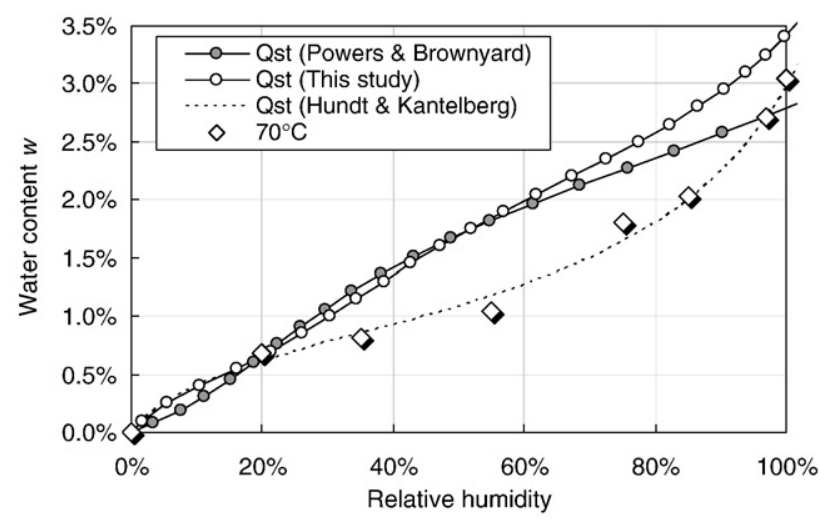

Fig. 13. Desorption isotherm at $70{ }^{\circ} \mathrm{C}$ of beton 5 estimated using the isosteric heat of sorption obtained in this study, proposed by Powers and Brownyard and derived from Hundt and Kantelberg. 


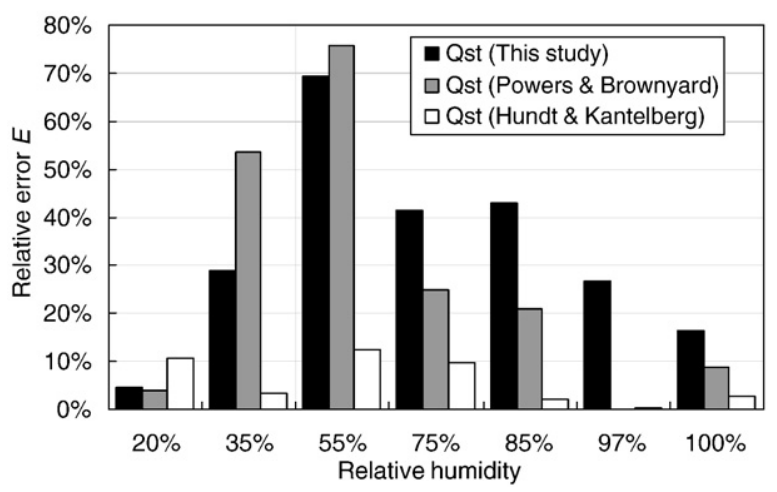

Fig. 14. Relative error between experimental water contents (at $70{ }^{\circ} \mathrm{C}$ for beton 5 [8]) and predicted values using three different isosteric heats of sorption.

Kantelberg [8]) can only be used to give a rough estimate of the impact of temperature on the desorption isotherm.

\section{Conclusion}

In the framework of radioactive waste management in France, concrete structures would be likely to undergo heating (up to $80^{\circ} \mathrm{C}$ ) and significant drying induced by the temperature increase. The durability assessment of such structures necessitates the knowledge of the evolution of the sorption isotherms versus temperature (in order to describe the induced water transfers).

This paper presents briefly the theoretical background needed to describe the impact of temperature on the sorption properties: the Clausius-Clapeyron equation and isosteric heat of sorption. The two of them allow describing the energy involved in the sorption process and then account for the impact of temperature on sorption isotherms. One can use CC to estimate the isosteric heat of sorption on the basis of the desorption isotherms obtained at only two different temperatures. One can then use the result obtained to compute the desorption isotherm at any other temperature. The consistency of the calculation depends on the quality of the experimental results used for the estimation of the isosteric heat.

The comparison between the evolutions of the isosteric heat of sorption obtained in this study (high-performance concrete) and previously published results shows a very similar pattern with values of the same order of magnitude. The three considered cementitious materials present the same general behaviour.

Nevertheless, the computation of the evolution of the desorption isotherm using CC proved to be very dependent on the isosteric heat of sorption: a reliable prediction of the sorption isotherms versus temperature requires the accurate knowledge of the isosteric heat of sorption for the material of interest. The use of a generic equation/ evolution (such as the one proposed by Powers and Brownyard) can only be used to yield an estimate of the impact of temperature on the desorption isotherms.

\section{Appendix A}

Table 1

Formulation of the high-performance concrete used by Poyet [4].

\begin{tabular}{lllll}
\hline Component & Nature & Origin & Quantity & Unit \\
\hline Cement & CEM I 52.5 & Lafarge Val d'Azergues, & 400 & $\mathrm{~kg} / \mathrm{m}^{3}$ \\
& & France & & \\
Sand & Calcareous [0-5] & Boulonnais quarry, France & 858 & $\mathrm{~kg} / \mathrm{m}^{3}$ \\
Gravel & Calcareous [5-12.5] & Boulonnais quarry, France & 945 & $\mathrm{~kg} / \mathrm{m}^{3}$ \\
Water & - & - & 172 & $\mathrm{~L} / \mathrm{m}^{3}$ \\
Superplasticizer & Glenium 27 & BASF & 10 & $\mathrm{~kg} / \mathrm{m}^{3}$ \\
\hline
\end{tabular}

Table 2

Data for the fitting of the experimental results obtained at $30{ }^{\circ} \mathrm{C}$ and $80^{\circ} \mathrm{C}[4]$.

\begin{tabular}{llll}
\hline Temperature $\left({ }^{\circ} \mathrm{C}\right)$ & $\mathrm{C}$ & $k$ & $w_{\mathrm{m}}(\%)$ \\
\hline 30 & 4.690 & 0.592 & 2.534 \\
80 & 6.010 & 0.897 & 0.480 \\
\hline
\end{tabular}

Table 3

Data for the fitting of the experimental results obtained by Hundt and Kantelberg [8].

\begin{tabular}{llll}
\hline Temperature $\left({ }^{\circ} \mathrm{C}\right)$ & $C$ & $k$ & $w_{\mathrm{m}}(\%)$ \\
\hline 20 & 16.794 & 0.507 & 2.364 \\
45 & 7.434 & 0.627 & 1.616 \\
57.5 & 6.400 & 0.679 & 1.239 \\
70 & 13.006 & 0.753 & 0.767 \\
\hline
\end{tabular}

Table 4

Isosteric heat of desorption obtained in this study.

\begin{tabular}{|c|c|c|}
\hline Water content $w(\%)$ & Coverage $w / w_{\mathrm{m}}$ & $Q_{s t}(w)[\mathrm{kJ} / \mathrm{mol}]$ \\
\hline 0.10 & 0.04 & 62.48 \\
\hline 0.25 & 0.10 & 65.56 \\
\hline 0.40 & 0.16 & 67.75 \\
\hline 0.55 & 0.22 & 68.49 \\
\hline 0.70 & 0.28 & 68.03 \\
\hline 0.85 & 0.34 & 66.91 \\
\hline 1.00 & 0.39 & 65.48 \\
\hline 1.15 & 0.45 & 63.92 \\
\hline 1.30 & 0.51 & 62.36 \\
\hline 1.45 & 0.57 & 60.83 \\
\hline 1.60 & 0.63 & 59.36 \\
\hline 1.75 & 0.69 & 57.97 \\
\hline 1.90 & 0.75 & 56.67 \\
\hline 2.05 & 0.81 & 55.45 \\
\hline 2.20 & 0.87 & 54.32 \\
\hline 2.35 & 0.93 & 53.27 \\
\hline 2.50 & 0.99 & 52.30 \\
\hline 2.65 & 1.05 & 51.40 \\
\hline 2.80 & 1.10 & 50.58 \\
\hline 2.95 & 1.16 & 49.81 \\
\hline 3.10 & 1.22 & 49.11 \\
\hline 3.25 & 1.28 & 48.46 \\
\hline 3.40 & 1.34 & 47.86 \\
\hline 3.55 & 1.40 & 47.30 \\
\hline 3.70 & 1.46 & 46.79 \\
\hline 3.85 & 1.52 & 46.31 \\
\hline 4.00 & 1.58 & 45.87 \\
\hline 4.15 & 1.64 & 45.45 \\
\hline 4.30 & 1.70 & 45.07 \\
\hline 4.45 & 1.76 & 44.71 \\
\hline 4.60 & 1.82 & 44.37 \\
\hline
\end{tabular}

The coverage is equal to the ratio between the water content $w$ and the monolayer capacity $w_{\mathrm{m}}$ obtained at $30^{\circ} \mathrm{C}$.

Table 5

Isosteric heat of desorption obtained for beton 5 on the basis of the results published by Hundt and Kantelberg [8].

\begin{tabular}{lllll}
\hline$w(\%)$ & $w / w_{\mathrm{m}}$ & \multicolumn{3}{l}{ Isosteric heat of desorption $Q_{\mathrm{st}}(w)[\mathrm{kJ} / \mathrm{mol}]$} \\
\cline { 3 - 5 } & & $20-70{ }^{\circ} \mathrm{C}$ & $45-57.5^{\circ} \mathrm{C}$ & All temperatures \\
\hline 0.08 & 0.03 & 60.04 & 66.54 & 62.64 \\
0.19 & 0.08 & 61.66 & 67.36 & 63.99 \\
0.30 & 0.13 & 63.49 & 68.16 & 65.48 \\
0.45 & 0.19 & 66.18 & 69.10 & 67.66 \\
0.61 & 0.26 & 68.86 & 69.79 & 69.79 \\
0.76 & 0.32 & 70.89 & 70.06 & 71.37 \\
0.91 & 0.38 & 71.82 & 69.80 & 72.04 \\
1.06 & 0.45 & 71.69 & 68.94 & 71.82 \\
1.21 & 0.51 & 70.80 & 67.54 & 70.93 \\
1.36 & 0.58 & 69.41 & 65.75 & 69.57 \\
1.51 & 0.64 & 67.71 & 63.75 & 67.90 \\
1.67 & 0.70 & 65.82 & 61.69 & 66.04 \\
1.82 & 0.77 & 63.84 & 59.70 & 64.07 \\
1.97 & 0.83 & 61.84 & 57.86 & 62.07 \\
\hline
\end{tabular}


Table 5 (continued)

\begin{tabular}{lllll}
\hline$w(\%)$ & $w / w_{\mathrm{m}}$ & \multicolumn{3}{l}{ Isosteric heat of desorption $Q_{\mathrm{st}}(w)[\mathrm{kJ} / \mathrm{mol}]$} \\
\cline { 3 - 5 } & & $50-70{ }^{\circ} \mathrm{C}$ & $45-57.5^{\circ} \mathrm{C}$ & All temperatures \\
\hline 2.12 & 0.90 & 59.88 & 56.18 & 60.09 \\
2.27 & 0.96 & 58.01 & 54.67 & 58.21 \\
2.42 & 1.02 & 56.27 & 53.33 & 56.44 \\
2.57 & 1.09 & 54.67 & 52.14 & 54.82 \\
2.72 & 1.15 & 53.23 & 51.09 & 53.36 \\
2.88 & 1.22 & 51.94 & 50.15 & 52.06 \\
3.03 & 1.28 & 50.79 & 49.32 & 50.89 \\
3.08 & 1.31 & 50.39 & 49.02 & 50.49 \\
3.14 & 1.33 & 50.01 & 48.75 & 50.10 \\
3.20 & 1.35 & 49.64 & 48.48 & 49.73 \\
3.26 & 1.38 & 49.29 & 48.22 & 49.37 \\
3.31 & 1.40 & 48.95 & 47.98 & 49.03 \\
3.37 & 1.43 & 48.63 & 47.74 & 48.71 \\
3.43 & 1.45 & 48.33 & 47.51 & 48.40 \\
3.48 & 1.47 & 48.03 & 47.29 & 48.10 \\
3.54 & 1.50 & 47.75 & 47.08 & 47.82 \\
3.60 & 1.52 & 47.48 & 46.88 & 47.54 \\
4.01 & 1.70 & 45.83 & 45.62 & 45.88 \\
4.54 & 1.92 & 44.27 & 44.39 & 44.31 \\
\hline
\end{tabular}

The coverage is equal to the ratio between the water content $w$ and the monolayer capacity $w_{\mathrm{m}}$ obtained at $20^{\circ} \mathrm{C}$. The reported temperatures correspond to the temperatures used for the estimation of the isosteric heat of sorption $Q_{\mathrm{st}}$.

\section{References}

[1] T.C. Powers, T.L. Brownyard, Studies of the physical properties of the hardened cement paste, Portland Cement Association Bulletin, vol. 22, 1948, 356p.

[2] H. Lagrave, Dossier de définition pour l'entreposage de longue durée des déchets HAVL et des combustibles usés (in french), CEA Internal Report DTEC/2005/10 (2005) 55p.

[3] H. Lagrave, Dossier de définition de l'entreposage de longue durée des déchets MAVL ou de catégorie B (in french), CEA Internal Report DTEC/2005/11 (2005) $63 p$

[4] S. Poyet, Experimental investigation of the effect of temperature on the first desorption isotherm of concrete, Cement and Concrete Research (in press), doi:10.1016/j.cemconres.2009.06.019.

[5] C. van der Berg, Vapour sorption equilibria and other water-starch interactions: a physico-chemical approach, Ph-D thesis, Agricultural University of Wageningen, The Netherlands, 1981, 186p.

[6] R.B. Anderson, Modifications of the Brunauer, Emmett and Teller equation, Journal of the American Chemical Society 68 (4) (1946) 686-691.

[7] S. Brunauer, J. Skalny, E.E. Bodor, Adsorption on non porous solids, Journal of Colloid and Interface Science 30 (4) (1969) 546-552.

[8] J. Hundt, H. Kantelberg, Sorptionsuntersuchungen an zemestein, zementmörtel und beton (in German), Deutscher Ausschuss für Stahlbeton Heft 297 (1978) 25-39.

[9] T. Ishida, K. Maekawa, T. Kishi, Enhanced modeling of moisture equilibrium and transport in cementitious materials under arbitrary temperature and relative humidity history, Cement and Concrete Research 37 (4) (2007) 565-578.

[10] S. Brunauer, The adsorption of gases and vapors, Physical Adsorption, vol. I, Princeton University Press, 1945, 511p.

[11] S.J. Gregg, Sixty years in the physical adsorption of gases, Colloids and Surfaces 21 (1986) 109-124.

[12] P. Atkins, J. de Paula, Atkin's Physical Chemistry8th edition, Oxford University Press, Oxford, 2006 1097p.

[13] S.J. Gregg, K.S.W. Sing, Adsorption, Surface Area and Porosity, Academic Press, London, 1982 303p.

[14] R.C. Bansal, M. Goyal, Activated Carbon Adsorption, CRC Press, 2005520 pp.

[15] A.A. Fomkin, Adsorption of gases, vapors and liquids by microporous adsorbents, Adsorption 11 (3) (2005) 425-436.

[16] S. Sircar, R. Mohr, C. Ristic, M.B. Rao, Isosteric heat of adsorption: theory and experiment, Journal of Physical Chemistry B 103 (31) (1999) 6539-6546.

[17] H. Pan, J.A. Ritter, P. Balbuena, Examination of the approximations used in determining the isosteric heat of adsorption from the Clausius-Clapeyron equation, Langmuir 14 (21) (1998) 6323-6327.

[18] K.N. Marsh (Ed.), Recommended Reference Materials for the Realization of Physicochemical Properties, Blackwell, Oxford, 1987, 510p.

[19] B.S. Nielsen, F.L. Kronholm, Physical bonds of water in hardened cement paste, Nordic Concrete Research 7 (1988) 207-221.
[20] F. Radjy, E.J. Sellevold, K.K. Hansen, Isosteric vapor pressure-temperature data for water sorption in hardened cement paste: enthalpy, entropy and sorption isotherms at different temperatures, Report BYG-DTU R057, Technical University of Denmark (DTU), Lyngby, 2003, 58p.

[21] E.J. Sellevold, Ø. Bjøntegaard, Coefficient of thermal expansion of cement paste and concrete: mechanisms of moisture interaction, Materials and Structures 39 (9) (2006) 809-815.

[22] F. Kaymak-Eterkin, M. Sultanoğlu, Moisture sorption isotherm characteristics of peppers, Journal of Food Engineering 47 (3) (2001) 225-231.

[23] M.D. Hossain, B.K. Bala, M.A. Hossain, M.R.A. Mondol, Sorption isotherms and heat of sorption of pineapple, Journal of Food Engineering 48 (2) (2001) 103-107.

[24] Z. Yan, M.J. Sousa-Gallagher, F.A.R. Oliveira, Sorption isotherms and moisture sorption hysteresis of intermediate moisture content banana, Journal of Food Engineering 86 (3) (2008) 342-348.

[25] C.P. McLaughlin, T.R.A. Magee, The determination of sorption isotherm and the isosteric heats of sorption for potatoes, Journal of Food Engineering 35 (3) (1998) 267-280.

[26] W.A.M. McMinn, T.R.A. Magee, Thermodynamic properties of moisture sorption of potato, Journal of Food Engineering 60 (2) (2003) 157-165.

[27] A. Jamali, M. Kouhila, L. Ait Mohamed, J.T. Jaouhari, A. Idlimam, N. Abdenouri, Sorption isotherms of Chenopodium ambrosioides leaves at three temperatures, Journal of Food Engineering 72 (1) (2006) 77-84.

[28] A. Iguaz, P. Vírseda, Moisture desorption isotherms of rough rice at high temperatures, Journal of Food Engineering 79 (3) (2007) 794-802.

[29] E. Berlin, B.A. Anderson, M.J. Pallansch, Effect of temperature on water vapour sorption by dried milk powders, Journal of Dairy Science 53 (2) (1970) 146-149.

[30] R. Moreira, G. Vázquez, G. Chenlo, Influence of the temperature on sorption isotherms of chickpea: evaluation of isosteric heat of sorption, Electronic Journal of Environmental, Agricultural and Food Chemistry (EJEAFChe) 1(1) (2002) available at http:// ejeafche.uvigo.es/index.php?option $=$ com_docman\&task=doc_download\&gid $=$ $13 \&$ Itemid $=33$.

[31] J.J. Fripiat, A. Jelli, G. Poncelet, J. André, Thermodynamic properties of adsorbed water molecules and electrical conduction in montmorillonites and silicas, Journal of Physical Chemistry 69 (7) (1965) 2185-2197.

[32] R.W. Mooney, A.G. Keenan, L.A. Wood, Adsorption of water vapor by montmorillonite I - heat of desorption and application of BET theory, Journal of the American Chemical Society 74 (6) (1952) 1367-1371.

[33] N. Hackerman, A.C. Hall, The adsorption of water vapor on quartz and calcite, Journal of Physical Chemistry 62 (10) (1959) 1212-1214.

[34] M.N. Mautner, Formation, chemistry and fertility of extraterrestrial soils: cohesion, water adsorption and surface area of carbonaceous chondrite. Prebiotic and space resource applications, Icarus 137 (1) (1999) 178-195.

[35] M.L. Corrin, J.A. Nelson, Energetics of the adsorption of water vapor on "pure" silver iodide, Journal of Physical Chemistry 72 (2) (1968) 643-645.

[36] M. Nagao, On physisorption of water on zinc oxide surface, Journal of Physical Chemistry 75 (25) (1971) 3822-3828.

[37] C. Pérez-Alonso, C.I. Beristain, C. Lobato-Calleros, M.E. Rodríguez-Huezo, E.J. VernonCarter, Thermodynamic analysis of the sorption isotherms of pure and blended carbohydrate polymers, Journal of Food Engineering 77 (4) (2006) 753-760.

[38] D.H. Olson, W.O. Haag, W.S. Borghard, Use of water as a probe of zeolitic properties: interaction of water with HZSM-5, Microporous and Mesoporous Materials 35-36 (2000) 435-446.

[39] B.L. Newalkar, R.V. Jasra, V. Kamath, S.G.T. Bhat, Sorption of water in aluminophosphate molecular sieve $\mathrm{AlPO}_{4-5}$, Microporous and Mesoporous Materials 20 (1-3) (1998) 129-137.

[40] J.K. Brennan, T.J. Bandosz, K.T. Thomson, K.E. Gubbins, Water in porous carbons, Colloids and Surfaces A: Physicochemical and Engineering Aspects 187-188 (2001) 539-568.

[41] I.I. Salame, T.J. Bandosz, Experimental study of water adsorption on activated carbons, Langmuir 15 (2) (1999) 587-593.

[42] I.I. Salame, T.J. Bandosz, Study of water adsorption on activated carbons with different degrees of surface oxidation, Journal of Colloid and Interface Science 210 (2) (1999) 367-374.

[43] I.I. Salame, T.J. Bandosz, Adsorption of water and methanol on micro- and mesoporous wood-based activated carbons, Langmuir 16 (12) (2000) 5435-5440.

[44] D. Myers, Surfaces, Interfaces and Colloids - Principles and Applications, John Wiley, New York, USA, 1999 519p.

[45] S. Timoumi, F. Zagrouba, D. Mihoubi, M.M. Tlili, Experimental study and modelling of water sorption/desorption isotherms on two agricultural products: apple and carrot, Journal de Physique IV 122 (2004) 235-240.

[46] D. Mihoubi, A. Bellagi, Thermodynamic analysis of sorption isotherms of bentonite, Journal of Chemical Thermodynamics 38 (9) (2006) 1105-1110.

[47] Z.Z. Zhang, P.F. Low, Relation between the heat of immersion and the initial water content of $\mathrm{Li}-, \mathrm{Na}$ - and $\mathrm{K}$-montmorillonite, Journal of Colloid and Interface Science 133 (2) (1989) 461-472. 